\title{
Study on Financial Management Model for Scientific Research
}

\author{
Hu Ouzhe ${ }^{1, a,{ }^{*}}$ \\ ${ }^{1}$ Department of Finance, Wuhan University of Technology, Wuhan 430070, Hubei, China \\ ahuouzhe@163.com \\ ${ }^{*}$ Corresponding author
}

Keywords: Financial Management; Models; Scientific Research; funding.

\begin{abstract}
Research activities have become an important part of today's society. How to effectively manage scientific research funding is the purpose of this research. This article first analyzes the necessity of establishing scientific research financial management model, and then introduces the content of scientific research financial management. Finally, it designs a simple and practical model for the scientific research financial management. The practical application shows that this model is of great help to the promotion of scientific research financial management in Chinese colleges and universities.
\end{abstract}

\section{Introduction}

Research funding has played a crucial role in promoting scientific research and technological development, and technological achievement transformation and promoting technological innovation. All along, with China's increasing emphasis on the development of scientific and technological innovation, the government's investment in scientific research has been increasing [1, 2]. Scientific research activities have become an important part of social activities and an important means to promote social development and progress.

The management of scientific research projects includes project application management in the early stage, mid-term research management, and later-stage results management. The management of scientific research funds is an important link in the management of scientific research projects. It always runs through the early, middle, and late stages of scientific research.

In recent years, the government has increased its support for scientific research activities. The proportion of research funds in the total social budget has increased year by year [3]. At the same time, the government has also introduced a large number of financial management policies and strengthened the management requirements for scientific research funds. In order to adapt to the society and make the scientific research activity process meet the government's management requirements, it is necessary to seek an effective financial management model for scientific research management $[4,5,6]$.

The projects are divided into vertical scientific research projects and horizontal scientific research projects according to the sources of funds for scientific research projects. The vertical scientific research projects refer to scientific research projects funded by government departments, which are divided into national-level key projects, national-level projects, provincial-municipal-level key projects, provincial and municipal-level projects, and division-level projects, school-fund projects and so on, according to different levels of funding $[7,8]$. The horizontal research projects refer to scientific research projects that are funded by enterprises. Because of the diversity of funding sources for scientific research projects, there are different financial management requirements [9, 10]. Different levels of vertical scientific research projects have specific document provisions and specific financial management regulations. Horizontal research projects are only required to meet the objectives of corporate research in accordance with the contract, and are looser in financial management than vertical research projects. However, in the actual financial management process, the funds for vertical scientific research projects cannot be fully implemented according to the relevant documents, and the horizontal research projects also have breach of contract responsibility. 
Therefore, we need to find a financial management method so that scientific research activities can be carried out in an orderly environment of guaranteed quality and quantity.

\section{Contents of Financial Management for Scientific Research}

The ultimate goal of financial management for scientific research is to maximize the benefits of the project sponsors, project undertakers, and the unit of the undertaker. As the financial management runs through the whole process of establishment, implementation and final acceptance of scientific research projects, therefore, the content of financial management for scientific research includes formulating project budgets according to the purpose of scientific research, supervising project management and project contracts, supervising the expenditures during the execution of projects, and finalizing the project funds when the project acceptance ends, and processing the balance funds and so on.

\subsection{Financial Management for Scientific Research in the early stage}

In the project establishment phase of the scientific research, the key to financial management is to properly formulate the project budget. The so-called rational budgeting is to realistically evaluate the cost of scientific research projects according to the needs of project implementation.

At present, there are obvious problems in the financial management for scientific research in the project establishment stage in China, which is mainly reflected in the fact that the budget for the project cannot fully reflect the costs necessary to obtain the expected results. Expenditure terms included in the budget are often inconsistent with the costs incurred in the actual implementation of the project. The reason for this distorted budget is that the originally reasonable budget expenditure clause may contradict the ongoing national policy at this stage.

For example, in the budget category, most projects do not allow the inclusion of labor costs in the budget, except for certain special item categories that clearly specify the labor costs. In practice, it is a well-known fact that all projects have a non-proportionate amount of labor expenses during the implementation process. Even in the categories of projects where the labor service fees are allowed to be included in the budget, the calculation method and the limitation of the expenditures are still not scientific and reasonable.

Therefore, the core content and difficulty of scientific research financial management in the project establishment stage lies in how to formulate a reasonable budget system and budget standards.

\subsection{Financial Management for Scientific Research in mid-term stage}

The financial management of the project implementation stage is the execution and continuation of the budget and its main basis is the specific provisions on the use of funds by the State's financial accounting policies and project contracts. The financial management at this stage mainly belongs to the technical level and is an important aspect of the process management of scientific research projects.

The main content of financial management at this stage is to supervise the project undertaker to implement it in accordance with the provisions of the project budget, and to ensure that the country's relevant financial accounting system is strictly observed during project implementation.

The main purpose of financial management in the implementation of the project is to ensure that the funds are in accordance with the stipulated expenses of the project sponsors in the project contract, and at the same time to avoid the risk of funding that the scientific research project may bring to bear the unit.

\subsection{Financial Management for Scientific Research in final stage}

The scientific research management in the final stage includes the acceptance of the results and the final accounts.

In the case of the normal implementation of the first two phases, the main content of the financial management in this stage is to prepare the final accounts report on the technical level. 
At the policy level, management policies should be formulated for the project financial final accounts. From the consideration of the unit's interests, the project must avoid risk operations during the implementation process. Therefore, the undertaking unit must establish an early-warning mechanism for the expenditure in the first two phases of the management policy. The main content of financial management in the final accounting stage is to formulate the reasonable distribution proportion of surplus funds.

\section{Financial Management Model for Scientific Research}

Through the foregoing introduction, we have already understood the content that scientific research financial management needs to solve. The author designs a set of financial management model which runs through the whole process of scientific research activities. Specifically, it includes a series of activities such as application for funds for scientific research projects, project implementation, project inspection and project final accounts.

\subsection{Model for Funds application}

As we all know, both vertical and horizontal research projects must prepare financial expenditure budgets at the beginning of their application. Government departments or enterprises find the most reasonable way to compare the budgets they have compiled to fund or cooperate. Then, if we want to obtain funding for scientific research, the preparation of a set of competitive budgets is a key step. How can you complete the task accurately and quickly? We need to establish a financial budget model for project application.

We illustrate the application of a vertical research project as an example.

First of all, we have to collect a large amount of historical data of the projects that have been approved for this project types used to build an expert database. The main content is the proportional relationship between the various expenditure expenses and the total expenses, i.e. the determination of the cost coefficients.

Second, it is necessary to familiarize with various regulations and set adjustment parameters for various expenditure budgets in accordance with the latest regulations. If there is data to show that the proportion of personnel expenses required by the government is enlarged, and the control of material testing fees is strengthened, then the proportion of material testing fees will be reduced and added to personnel expenses.

In addition, it is necessary to consider that different disciplines have different characteristics. For example, the proportion of travel expenses in the humanities discipline is greater than the proportion of travel expenses in engineering disciplines, and the proportion of material test fees in the same engineering disciplines is greater than that in the humanities disciplines.

The data model is as follows:

Set total Funding $=Q_{i}$; expenses $=A_{i}, B_{i}, C_{i,} \ldots$; cost factor $=W_{A}, W_{B}, W_{C}, \ldots$, then:

$$
W_{A}=\frac{\sum_{i=1}^{n} A_{i} / Q_{i}}{n} \times 100 \%
$$

Other cost factors $W_{B}, W_{C}, \ldots$ are also calculated as above.

After calculating all the cost factors $W$, we can calculate all the budgets of the projects that we want to apply for. The calculation model is as follows:

Let's take the cost $A$ as an example. Set the adjustment parameter $=Z_{A}$, then:

$$
A=Q \times\left(W_{A}+Z_{A}\right)
$$

The other costs $B, C, \ldots$ are also calculated as above.

The sum of the various types of costs $A, B, C, \ldots$ calculated above is the total budgeted expenditure $Q$. 
After the budget calculation database is established, as long as the total amount of funds for the application project is determined, the budget plan for the application project can be accurately and quickly completed.

\subsection{Adjustment of research budget management model}

After the project application is approved, the approved funds are often different from the reported budget amount, and adjustments need to be made accordingly.

At this time, we can also use the above application budget model to adjust the budget. The new budgetary expenses can be calculated by multiplying the total amount of funds approved by the superior and the various cost factors determined in the budget.

Calculating the adjusted budget in this way is often very easy to approve, scientific research funding will naturally be put in place quickly, and scientific research work will be carried out smoothly.

\subsection{Management model of scientific research funds}

In general, project funds are allocated in batches. When the government's first batch of funds is in place, the finance department should immediately establish a separate project code for each project according to the special fund-specific principle. Under the corresponding project code, a financial index account is established according to the amount of project budget, and the expenditure of project funds is controlled. At this time, the control is on the total amount, because different periods of time, scientific research projects have different funding needs, it is impossible for the equal proportion of expenditure in each period. Therefore, we can only control the total amount. Afterwards, the funds can be directly accounted for under the established project code.

We need to use the accounting process model for project accounting. The block diagram of this model is shown in Fig. 1.

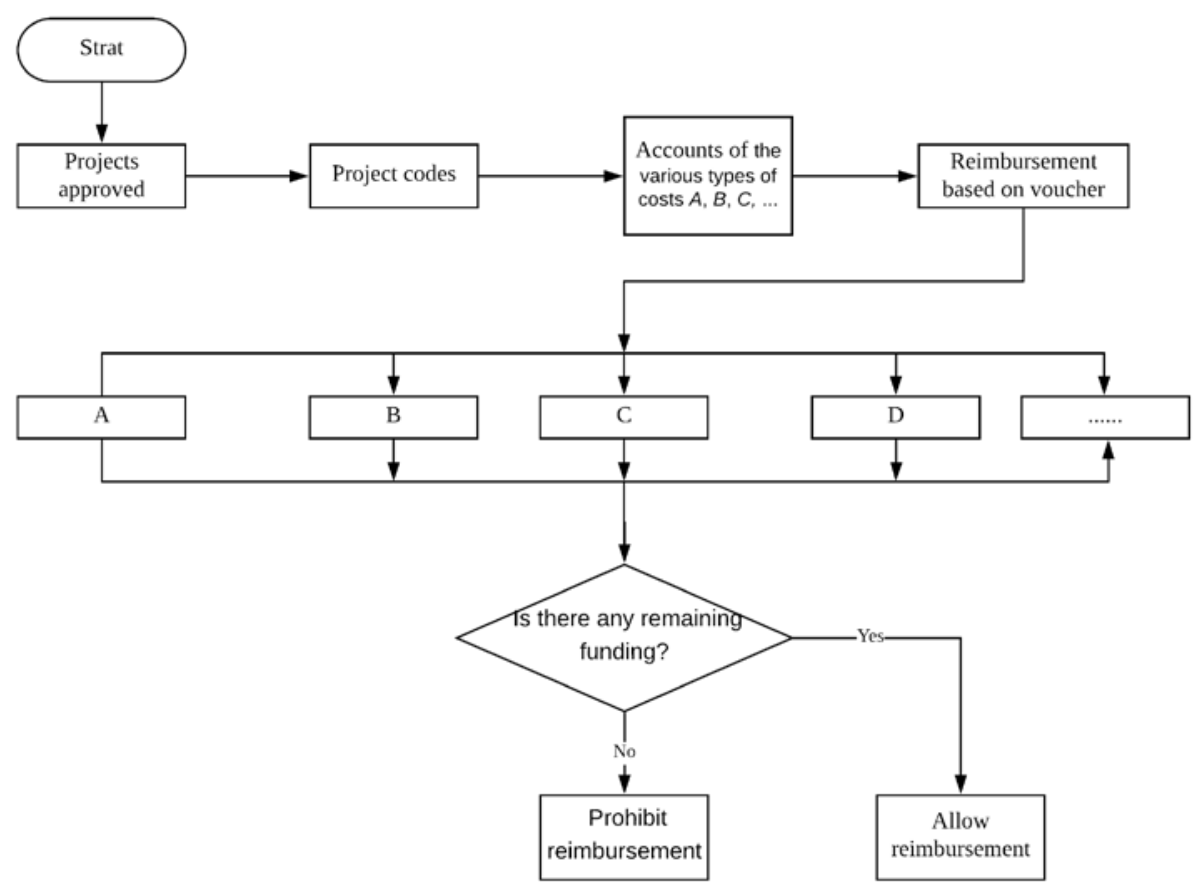

Fig.1 Block diagram of management model of scientific research funds

We have defined the funding budget for scientific research projects at the beginning of the project, and also defined the total amount of expenses for various types of expenses through a computer program. Even if the scientific research project undertaker forgets the amount of the project budget, our financial management model will also prompt to ensure that the scientific research project is executed strictly in accordance with the budget and the contract. 
After the expiry of the implementation of the scientific research project, the project will be completed and the use of funds for research projects will be reported. For funds, it is to check whether scientific research funds are used in accordance with the requirements of the budget and require the production of true financial statements for project expenditures. Because of the control and management of the above steps, the expenditure on scientific research cannot exceed the budget. Therefore, for the final accounts, as long as they are collected and summarized according to the contents of the accounting treatment, a complete and true financial statement can be obtained.

\section{Summary}

The conclusion that science and technology are productive forces has been fully demonstrated in today's society. Scientific research activities have an increasing impact on the society. Only by using scientific research funds well can we promote the rapid and healthy development of the society. In this paper, a set of financial management model of scientific research is established according to the actual situation of scientific research in Chinese universities. The practical application shows that this model is of great help to the financial management of scientific research in colleges and universities.

\section{References}

[1] Ruan Xingqiang. The problems existing in research funds in universities and their countermeasures. Friends of Accounting, vol. 10, pp. 23-26,2013.

[2] Chen Hui. Dilemma and Optimizing Path of Research Fund Management in Colleges and Universities. Accounting Learning. vol. 12, pp. 204-205, 2018.

[3] Zhang Li. Problems and Countermeasures in Scientific Research Management in Colleges and Universities. Educational Theory and Practice. vol. 24, pp. 15-16, 2017.

[4] He Jianchao. Problems and Countermeasures in the Management of Scientific Research Funds in Universities. Chinese and Foreign Exchange. vol. 1, pp. 3-6, 2018.

[5] Lu Haiqing. Research on the Management of Research Funds in Colleges and Universities. Accountant. vol. 12) :66-68, 2016.

[6] Xia Jing. Research on multi-level scientific research funds management mode in colleges and universities. Finance and Accounting Communications. vol. 25, pp. 53-56, 2017.

[7] Zhao Shanqing. Strengthening the Strategy of Scientific Research Fund Management in Universities. Finance and Accounting Monthly. vol. 2, pp. 49-52, 2015.

[8] Zhao Lin, Chen Zhibin, Liu Yu, Li Xuemeng. Fine Management of Research Funds in Colleges and Universities. Finance and Accounting Communications. vol. 17, pp. 125-126, 2015

[9] Han Yingxia. Using Management Accounting to Strengthen the Management of Scientific Research Funds in Colleges and Universities. Finance and Accounting. vol. 8, pp. 66, 2017.

[10] Yang Yan; Chen Jie. Research on Strengthening the Management of Research Funds in Colleges and Universities. Financial and Economic Circles (Academic Edition). vol. 8, pp. 46-47, 2018. 